\title{
The Effect of Argon Inert Gas on the Laser Welding Quality of Co-Cr and Ni-Cr Base Metal Alloys
}

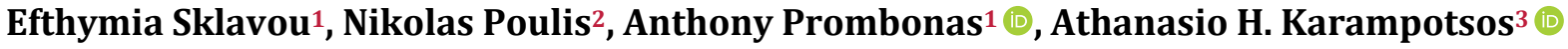 \\ ${ }^{1}$ Division of Dental Technology, Department of Biomedical Sciences, School of Health and Care Sciences, University \\ of West Attica, Athens, Greece; ${ }^{2}$ Centre for Dental Sciences, Faculty of Health and Wellbeing, University of Bolton, \\ Manchester, UK; ${ }^{3}$ Department of Conservation of Antiquities and Works of Arts, School of Applied Arts \& Culture, \\ University of West Attica, Athens, Greece
}

Correspondence to: Prombonas Anthony, aprob@uniwa.gr

Keywords: Laser Welding, Co-Cr Alloys, Ni-Cr Alloys, Mechanical Properties, Argon, No Argon Environment

Received: October 29, $2021 \quad$ Accepted: December 25, $2021 \quad$ Published: December 28, 2021

Copyright $\odot 2021$ by author(s) and Scientific Research Publishing Inc.

This work is licensed under the Creative Commons Attribution International License (CC BY 4.0).

http://creativecommons.org/licenses/by/4.0/

\section{(c) (1) Open Access}

\section{ABSTRACT}

The purpose of this research was to study the effect of Argon inert gas on the laser welding quality of $\mathrm{Co}-\mathrm{Cr}$ and $\mathrm{Ni}-\mathrm{Cr}$ base metal alloys, which are widely used as Fixed Prosthodontics alloys in Dental Laboratories. A total of 36 specimens were manufactured (18 of Ni-Cr alloy and 18 of Co-Cr alloy). The specimens were then divided into 3 subgroups (6 specimens each): control; argon-welded; and non-Argon welded. The specimens were cut, laser welded, radiographed and finally tested under tensile strength testing, followed by examination using Scanning Electron Microscopy. The tensile strength of welded specimens was lower than the strength of non-welded specimens, however this difference was not found to be statistically significant. The material factor (Co-Cr alloy or $\mathrm{Ni}-\mathrm{Cr}$ alloy) has a statistically significant effect on the tensile strength, while the presence or not of the inert gas, as well as the combination of the two factors do not have a statistically significant effect. The laser welding process applied in daily practice (separation of specimen, formation of two cones in contact, aggregation of two cones, filling of the remaining gap by welding) is considered satisfactory in terms of weld strength. The factor of the material, as an independent factor, affects the tensile strength to a statistically significant degree, in contrast to the factor of the presence of inert gas which does not affect to a statistically significant degree.

\section{INTRODUCTION}

The need for improved and functional prosthetic restorations was the primary reason for the development of dental alloys and appropriate welding materials that increase the strength of dental prostheses. This need for durable additives but also the requirement for low-cost alloys, led to the predominance of 
base metal alloys and in particular $\mathrm{Co}-\mathrm{Cr}$ and $\mathrm{Ni}-\mathrm{Cr}$ alloys. These alloys have improved properties such as modulus of elasticity, durability, corrosion resistance and low density. These are a few of the base metal alloy characteristics that lead to the manufacture of thinner, lighter and more durable dental appliances in comparison to gold alloys.

A factor that is required to be taken into consideration by the dental technicians during the manufacture of prosthetic restorations is the moment of casting. If care is not taken, there is a risk of overheating the alloy which can lead to casting failures, to the extent that these restorations cannot be inserted into the oral cavity [1-3].

In the event of casting mishandling, casting defects may occur (e.g., microporosity) posing a risk that the prosthetic restoration will break in a weak point, due to the accumulation of stresses and the repeated bending fatigue $[4,5]$.

Therefore, key factors that influence the quality of such a prosthetic restoration are:

1) The chemical composition of the alloy

2) The physicochemical composition

3) The metallographic structure

4) The mechanical behaviour of the alloy determined by its mechanical properties

Defects in the structure of cast prostheses and stress concentration areas (porosity, foreign bodies, investment, etc.) are often observed. In addition, loading of the prosthetic restorations is conducted through cyclically repeated loads, causing fatigue and finally leading to their fracture. Fractures can also occur by an accident (e.g., drop and impact). In such instances, proper welding should be conducted, both in terms of strength and accuracy [6-11].

Many and important are the researches that have been done from time to time on the subject of the resistance of the welds of the basic dental alloys with laser [12-26]. In most researches, the specimens have been cut in the middle, the two pieces have been held in contact with the help of a special base and then the welding was done with penetration of the laser beam, in order to evaluate the quality (strength) of the welding. In a small number of researches, the beveling of the ends of the two pieces with the creation of an X-shaped flap has also been studied [27-39].

The purpose of this research was to study the effect of Argon inert gas on the laser welding quality of $\mathrm{Co}-\mathrm{Cr}$ and Ni-Cr base metal alloys, which are widely used as Fixed Prosthodontics alloys in Dental Laboratories. Furthermore, the scope of the research was to compare the process of laser welding applied in the daily practice (separation of the prosthetic work, immobilization of the two pieces in the oral cavity, transfer on to a new cast, formation of two cones in contact on the side walls of the separation point using the welding material, agglomeration of the two cones with one or more laser attacks), with process used in the previous researches.

\section{MATERIALS AND METHODS}

\subsection{Specimens' Preparation}

Thirty-six specimens were manufactured using a special machinable wax via the subtraction method from a wax disc using a special milling machine (CAD/CAM) (Figure 1). The thickness of each specimen was $3 \mathrm{~mm}$ and the total length $42 \mathrm{~mm}$, according to the ISO 6892 specification. Two dental alloys were used to cast the wax specimens. A Co-Cr alloy (Auriloy N.P. Supreme, Aurium Research, San Diego, California, USA) and a Ni-Cr alloy (Auriloy NP Star, Aurium Research, San Diego, California, USA). The composition provided by the company for the Co-Cr alloy was Co 61\%, Cr 27\%, Mo 6\%, Si 1\%, C(x), W $5 \%$, Mo 6\%, $\mathrm{Fe}(\mathrm{x}), \mathrm{Mn}(\mathrm{x})$ while for the Ni-Cr was Ni 61.2\%, Cr 25.8\%, Mo 11\%, Si\% 1.5\%, Al(x), Mn(x). The laser-welded group specimens were cut and welded using a special jig. Two laser welding wires were used, one for the Co-Cr alloy (LWNPCo, Aurium Research, San Diego, California, USA) and one for the Ni-Cr alloy (LWNPNi, Aurium Research, San Diego, California, USA), with compositions similar to those of the parent alloys. 


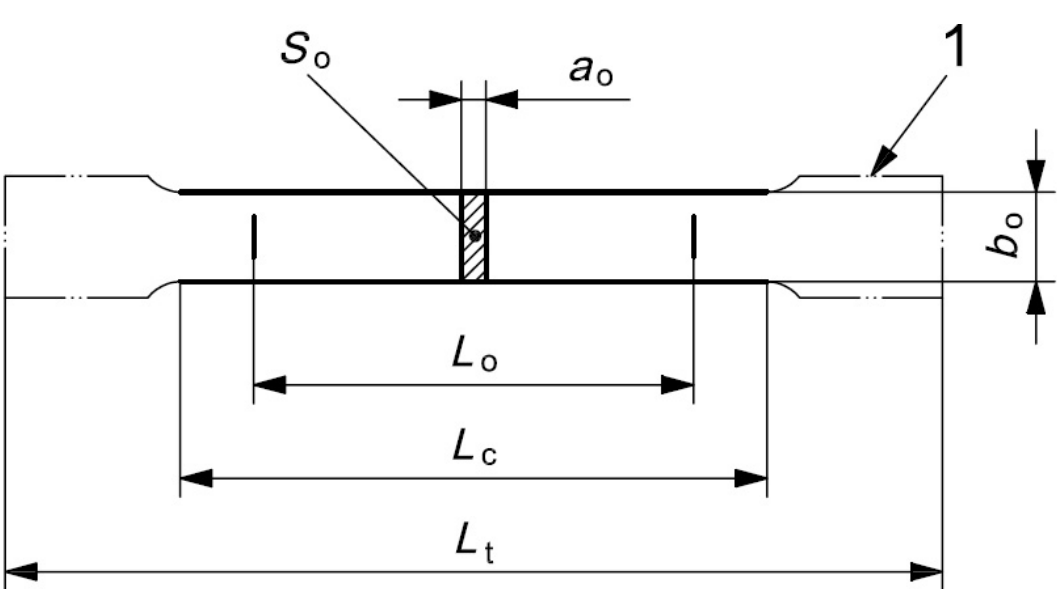

(a)

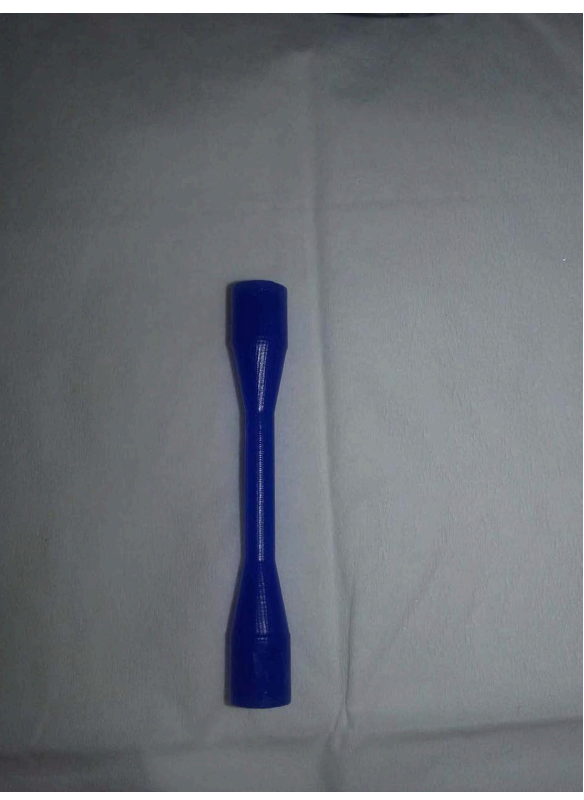

(b)

Figure 1. (a) Illustration of the specimen, from

https://regbar.com/wp-content/uploads/2019/09/ISO-6892-1-2009.pdf (b) Wax specimen manufactured via CAD/CAM (subtractive manufacturing).

\subsection{Radiographic Evaluation}

In order to evaluate the degree of porosity of the cast alloys, all specimens were examined using X-rays (General Medical Merate SpA CPI-CMP20, Seriate, Bergamo, Italy). The specimens were placed on a digital X-ray plate (Fuji Film FCR Capsula X Digitizer, Fuji Film, Tokyo, Japan) and irradiated (90 kV, $71 \mathrm{mAs}$, with head distance from the plate $66 \mathrm{~cm}$ ).

The shape and size of the specimens did not allow the detection of small pores which were eventually detected and observed in the fractography.

\subsection{Welding}

The test specimens, after casting, were cut via a $0.5 \mathrm{~mm}$ thick cutting disc and welded to a specially designed and fabricated base for this purpose (Laser Star Riverside RI 02915, Orlando, USA). The device settings were: peak power $260 \mathrm{~V}$, pulse duration $3.5 \mathrm{~ms}$ pulse repetition $1.5 \mathrm{~Hz}$ and spot diameter $0.2 \mathrm{~mm}$. Then, one half of the cut specimen was detached from the jig and a cone was formed in the center of its cross-section by laser welding. Similarly, the same cone was formed on the other part of the cut specimen. When the two pieces were placed back onto the jig, and the two cones formed in the cut area were in light contact, the laser welding of the specimen begun. After the initial welding of the cones and the formation of an X-shaped bevel, the remaining gaps were further filled by laser welding (Figure 2). After the laser welding, the specimens were lightly ground via a special grinding disc ( $4 \mathrm{~mm}$ thick) to smoothen the surface of the weld. During this process, a continuous rotational motion was utilized to maintain the cylindrical shape of the specimen.

\subsection{Tensile Strength Testing}

The specimens were tested on a Universal Testing machine (Instron6022, Norwood, USA) and the tensile strength and elongation were then calculated. The crosshead speed was set at $1.5 \mathrm{~mm} / \mathrm{min}$. The $80 \%$ of the specimens fractured in the welded area. 


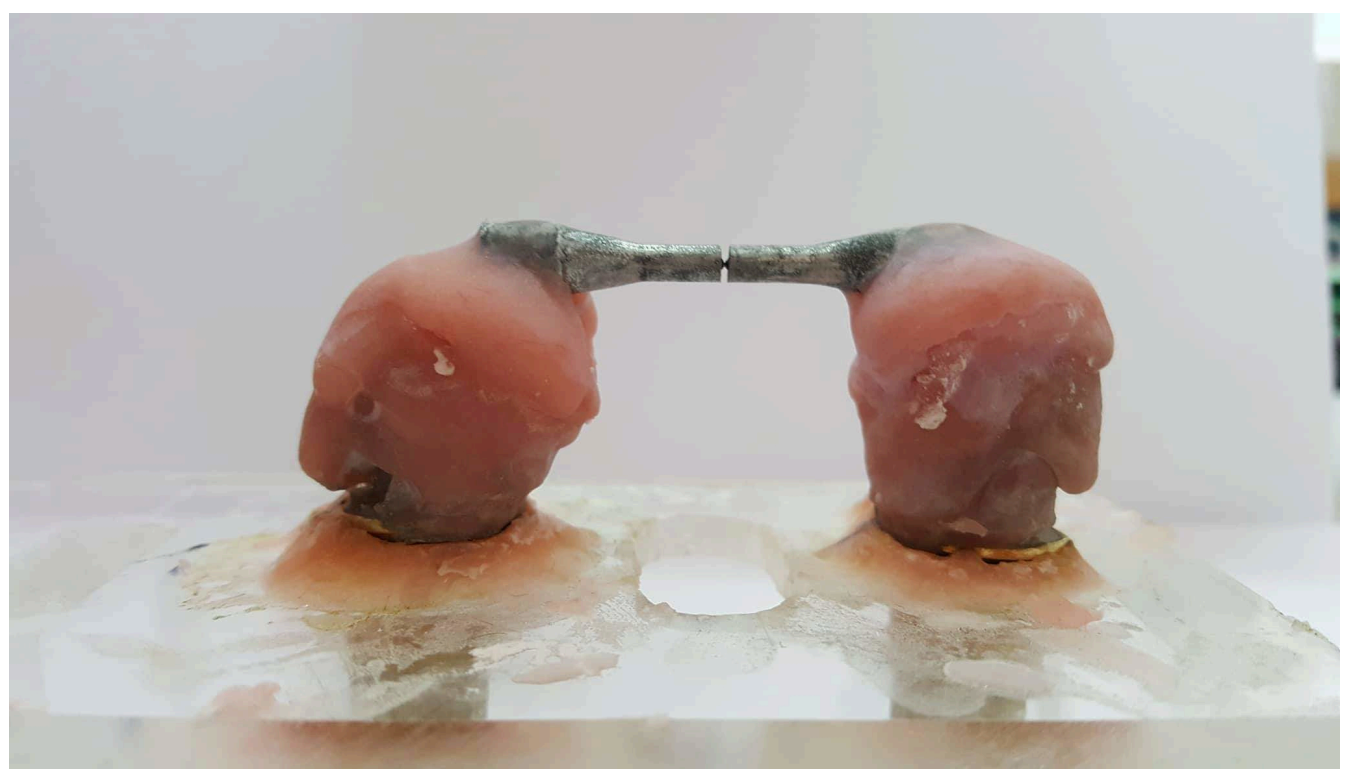

Figure 2. The cut area and the formation of the cones are displayed. The corresponding laser welding wire was used to fill the gaps created.

\subsection{Fractography}

After the specimens were fractured, the fractured surface was evaluated to assess the morphology of the welded areas. With the utilisation of the Scanning Electron Microscope (JEOL JSM 6510 QLV, Peabody, USA) a fractographic analysis was performed on the welded areas.

\subsection{Statistical Analysis}

SPSS 15 for Windows (SPSS Inc., Chicago, USA) was used to statistically evaluate the results.

Due to the low number of specimens (eight), nonparametric tests were applied for statistical analysis, using standard statistical software (SPSS version 15.0 for Windows, SPSS, Chicago, Illinois, USA). The Kruskal-Wallis test was used to assess variations of the means among the 6 different groups. The Wilcoxon test was used to determine the significance of differences in the stress magnitudes between all possible pairs of notch conditions, with a probability cut-off of $P=0.05$.

In order to better document this research finding, mainly from a statistical point of view, the statistical evaluation of a multifactorial experiment without repetition of measurements (that means on different specimens) (factorial experiment) was applied. The statistical method simultaneously examined the effect of two factors, the presence or absence of inert gas and the material utilised (type of alloy). These two factors were examined both independently (influence of only the material or only the presence of inert gas) but also in combination (effect of both factors simultaneously.

\section{RESULTS}

\subsection{Descriptive Statistics}

Table 1 shows the fracture values of the specimens for each group.

Table 2 lists the tensile strength values of the specimens for each group.

Table 3 shows the complete data of the descriptive statistics for all groups as they were calculated by the statistical program SPSS Statistics.

Table 4 presents the results for both the Kruskall-Wallis statistical test and the Mann-Whitney statistical test in all possible pairwise comparisons. The differences that are statistically significant $(P<0.05)$ are marked in bold. 
Table 1. Fracture values of all groups (in Newtons).

\begin{tabular}{ccccccc}
$\begin{array}{c}\text { Group } \\
\text { Spec no. }\end{array}$ & Co-Cr & Co-Cr/NoAr & Co-Cr/Ar & Ni-Cr & Ni-Cr/NoAr & Ni-Cr/Ar \\
\hline 1 & $4860 \mathrm{~N}$ & $5268 \mathrm{~N}$ & $6013 \mathrm{~N}$ & $5098 \mathrm{~N}$ & $4877 \mathrm{~N}$ & $4567 \mathrm{~N}$ \\
2 & $4475 \mathrm{~N}$ & $5892 \mathrm{~N}$ & $5189 \mathrm{~N}$ & $4924 \mathrm{~N}$ & $5015 \mathrm{~N}$ & $5118 \mathrm{~N}$ \\
3 & $4944 \mathrm{~N}$ & $5033 \mathrm{~N}$ & $5393 \mathrm{~N}$ & $4624 \mathrm{~N}$ & $5119 \mathrm{~N}$ & $4803 \mathrm{~N}$ \\
4 & $4987 \mathrm{~N}$ & $4977 \mathrm{~N}$ & $5308 \mathrm{~N}$ & $4598 \mathrm{~N}$ & $4661 \mathrm{~N}$ & $4806 \mathrm{~N}$ \\
5 & $4956 \mathrm{~N}$ & $5323 \mathrm{~N}$ & $4714 \mathrm{~N}$ & $4819 \mathrm{~N}$ & $5076 \mathrm{~N}$ & $4865 \mathrm{~N}$ \\
6 & $4899 \mathrm{~N}$ & $5489 \mathrm{~N}$ & $4476 \mathrm{~N}$ & $4160 \mathrm{~N}$ & $5036 \mathrm{~N}$ & $4689 \mathrm{~N}$ \\
\hline
\end{tabular}

Table 2. The calculated tensile strength values for all specimens in MPa.

\begin{tabular}{cccccc}
\hline Co-Cr & Co-Cr/NoAr & Co-Cr/Ar & Ni-Cr & Ni-Cr/NoAr & Ni-Cr/Ar \\
\hline 687 & 475 & 851 & 721 & 690 & 646 \\
633 & 833 & 734 & 696 & 709 & 724 \\
699 & 712 & 763 & 654 & 724 & 679 \\
705 & 704 & 751 & 650 & 659 & 680 \\
701 & 753 & 667 & 682 & 718 & 688 \\
693 & 776 & 633 & 588 & 712 & 663 \\
\hline
\end{tabular}

Table 3. Data of the descriptive statistics for all groups.

\begin{tabular}{ccccccc}
\hline & $\mathrm{N}$ & Range & Minimum & Maximum & Mean & Std. Devia- \\
\hline & Statistic & Statistic & Statistic & Statistic & Statistic & Statistic \\
\hline Co-Cr & 6 & 72.00 & 633.00 & 705.00 & 686.3333 & 26.88246 \\
Co-Cr/NoArgon & 6 & 358.00 & 475.00 & 833.00 & 708.8333 & 123.76658 \\
Co-Cr/Argon & 6 & 218.00 & 633.00 & 851.00 & 733.1667 & 76.81775 \\
Ni-Cr & 6 & 133.00 & 588.00 & 721.00 & 665.1667 & 46.17539 \\
Ni-Cr/NoArgon & 6 & 65.00 & 659.00 & 724.00 & 702.0000 & 24.00833 \\
Ni-Cr/Argon & 6 & 78.00 & 646.00 & 724.00 & 680.0000 & 26.25262 \\
Valid N (listwise) & 6 & & & & & \\
\hline
\end{tabular}

Table 4. Statistical Evaluation of Results

\begin{tabular}{ccccccc}
\hline & $\mathrm{Co}-\mathrm{Cr}$ & $\mathrm{Co}-\mathrm{Cr} / \mathrm{No} \mathrm{Ar}$ & $\mathrm{Co}-\mathrm{Cr} / \mathrm{Ar}$ & $\mathrm{Ni}-\mathrm{Cr}$ & $\mathrm{Ni}-\mathrm{Cr} / \mathrm{NoAr}$ & $\mathrm{Ni}-\mathrm{Cr} / \mathrm{Ar}$ \\
\hline $\mathrm{Co}-\mathrm{Cr}$ & & 0.150 & 0.150 & 0.337 & $\mathbf{0 . 0 0 4}$ & $\mathbf{0 . 0 0 4}$ \\
$\mathrm{Co}-\mathrm{Cr} / \mathrm{NoAr}$ & & & 0.631 & 0.575 & $\mathbf{0 . 0 2}$ & $\mathbf{0 . 0 0 6}$ \\
$\mathrm{Co}-\mathrm{Cr} / \mathrm{Ar}$ & & & & 0.337 & 0.262 & 0.078 \\
$\mathrm{Ni}-\mathrm{Cr}$ & & & & 0.037 & $\mathbf{0 . 0 0 6}$ \\
$\mathrm{Ni}-\mathrm{Cr} / \mathrm{NoAr}$ & & & & & & 0.078 \\
$\mathrm{Ni}-\mathrm{Cr} / \mathrm{Ar}$ & & & & & \\
\hline
\end{tabular}

Evaluation of the variance by Kruskall-Wallis $P=0.002$. Evaluation of the difference in mean values between all possible pairs between groups according to Mann-Whitney. 


\subsection{Fractography}

Fragmentation of selected fractured specimens post-welding is shown in Figure 3.

$\mathrm{Ni}-\mathrm{Cr}$ with Argon: More plastic deformation is observed. A circular layering without homogenization is observed. In particular, the alloy is arranged in circular concentric regions which are not homogenized, which means they have voids which also have circular concentric orbits. In the center of the specimen there is good homogenization of the alloy (no voids present). As the layering develops (moving towards the outer layers), the homogenisation improves, with a reduction of the concentric gaps.

$\mathrm{Ni}-\mathrm{Cr}$ without Argon: The fracture that occurred over the bonding area shows the characteristic circular layering of the alloy with concentric circles (presenting gaps between them in the same circular arrangement). Better homogenization of the alloy without voids and cracks is observed in the center of the specimen and in the periphery.

Co-Cr with Argon: In the fracture area that took place in the welded area, there is a circular layering of the welded alloy not presenting good homogenization. In the center, it appears that the homogenization is of higher degree without voids and cracks, while some porosity is also observed. Similarly, there are areas of the circular layers-rings of the welded alloy, where penetration in a radial direction in between the layers is observed.

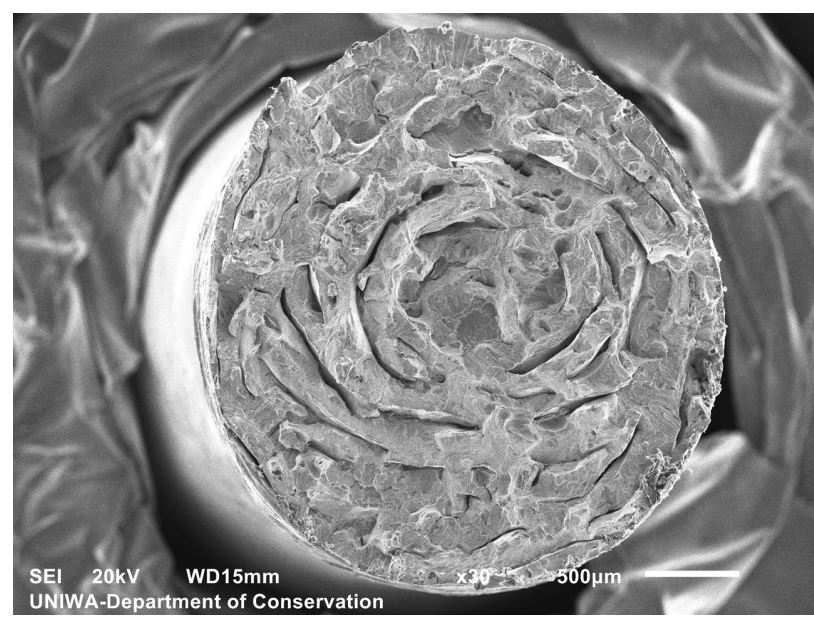

(a)

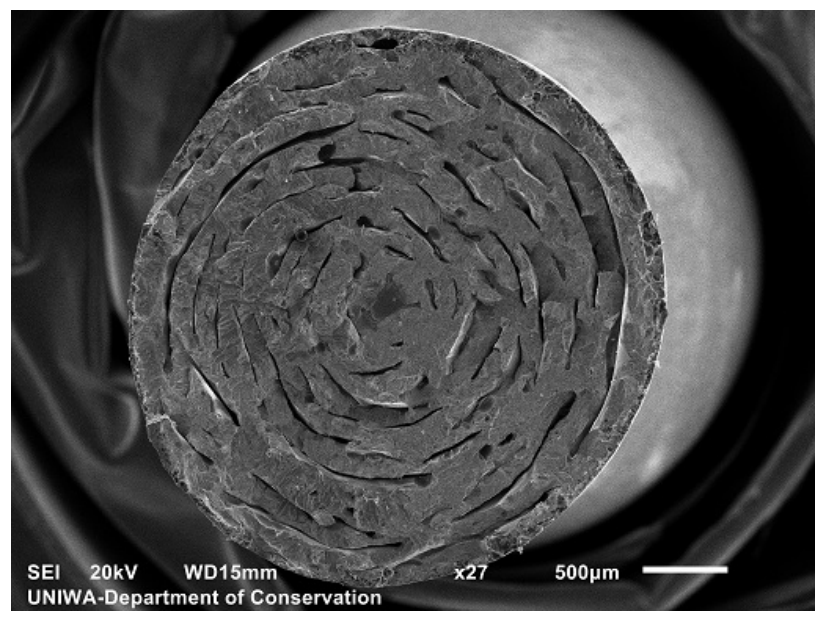

(c)

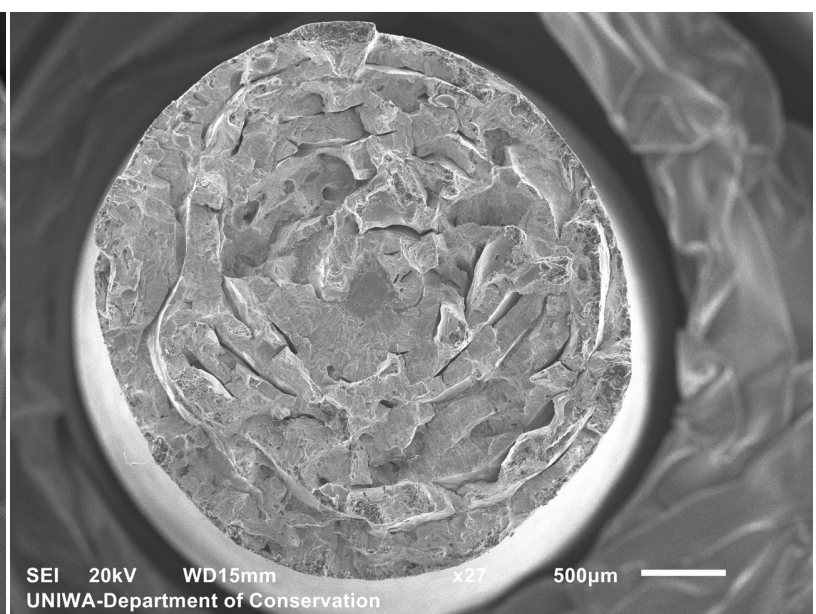

(b)

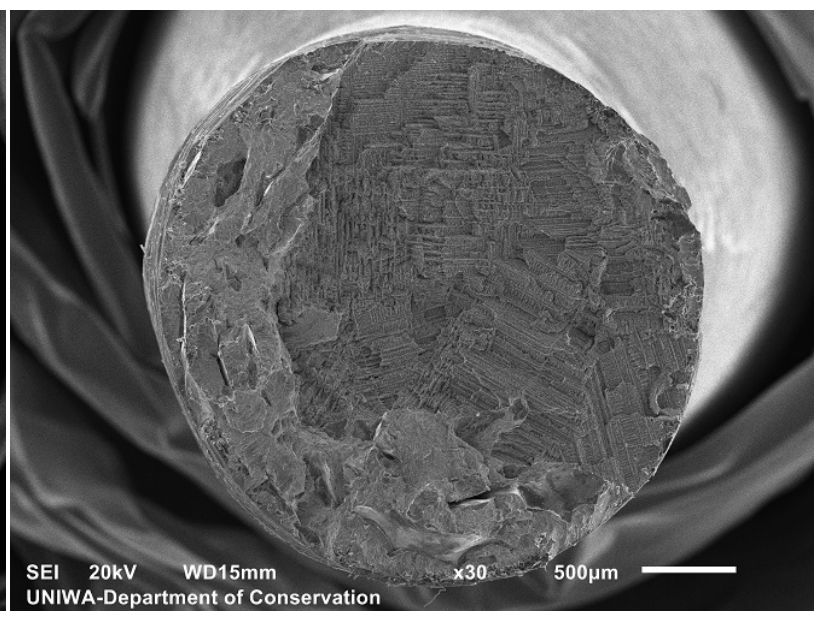

(d)

Figure 3. SEM images of selected representative fractured specimens post-welding: (a) Ni-Cr with Argon, (b) Ni-Cr without Argon, (c) Co-Cr with Argon, (d) Co-Cr without Argon. 
Co-Cr without Argon: This specimen's image shows a more brittle fracture (compared to the Ni-Cr alloy), while better homogenisation can also be seen. Traces of circular layering of the alloy (arrangement in circular concentric rings-layers) are visible, while no clear dendritic structure is observed.

\section{DISCUSSION}

The longevity and mechanical behaviour of the restorations, apart from the required proper design (avoidance of stress concentration areas), also depend on the structural continuity of the alloy after casting. As laboratory casting may present various defects, it is always possible to fracture due to the concentration of stresses and flexural fatigue that takes place during functional use [4, 9, 38]. In cases of fracture, the laser technology used for welding the fractured parts of the restoration is of utmost importance. It is very important to investigate the strength of laser welds to improve the longevity of welded restorations $[4$, $9,38]$.

The radiographic examination that was performed showed macroscopic structural continuity of the specimens for all groups. This assessment was conducted because according to other research, several pores were observed in the main mass of the specimens, but also in the welded area [11-19]. In this research the specimens were made by the CAD/CAM method, using laminated wax, which were then invested, in order to increase the accuracy of dimensions. On radiographic examination, it appeared that there was no development of large pores in the specimens.

Regarding the tensile strength of the welded specimens in the present study, this was shown to be less than the tensile strength of the non-welded specimens, however this difference was not found to be statistically significant. This finding applies to both $\mathrm{Co}-\mathrm{Cr}$ and $\mathrm{Ni}-\mathrm{Cr}$ alloys. A review of the available to us literature shows that most researchers agree that non-welded specimens are more durable than laser welded specimens. The reason for this finding is attributed to the poor penetration of the laser beam, given that the specimens in these studies were cut and repositioned with their cut ends in contact for welding [12, 15, $32,35,36,38]$.

The largest variation between the resistance values was observed in the groups.

All studies support the fact that the final fracture strength decreases after welding. This finding is common to all studies regardless of differences in specimen design and load testing. These findings are attributed to a variety of parameters, e.g., pore development, incomplete welding penetration, melting during laser welding, welding parameters, experience of the technologist, etc. [13-21, 34-39].

The presence of argon inert gas was found to cause a decrease in tensile strength when compared to the absence of argon inert gas, however this difference was not found to be statistically significant. In the available to us literature, it seems that opinions on the same subject matter differ, as some researchers consider the presence of inert gas to be beneficial (improving the tensile strength of the weld) while other researchers consider it not presenting any difference $[12,14,38,39]$.

Using the multifactorial experiment without repetition of measurements (that means on different specimens) (factorial experiment) was applied and the simultaneous examination of the effect of two factors, the presence or absence of inert gas and the material utilised (type of alloy), was made. These two factors were examined both independently (influence of only the material or only the presence of inert gas) but also in combination (effect of both factors simultaneously). It has been shown that the factor of the material, as an independent factor, affects the tensile strength to a statistically significant degree, in contrast to the factor of the presence of inert gas which does not affect to a statistically significant degree. This is in agreement to other researchers arguing that the alloying agent (material) determines the bond strength of basic alloys by laser and not the presence of inert gas [12, 14, 38, 39]. In addition, it has been shown that neither the combined effect of both of the above factors has an effect on the strength of the welds to a statistically significant degree.

However, the fractography revealed microporosity and microcracks in almost all specimens, a fact which is attributed to the nature of laser welding taking place in the laboratory, where apart from the quality of the laser welding device and the welding parameters set, the technologist's skills also affect the final 
laser welding quality. It is proposed to change the welding parameters during the welding process after the initial welding of the cones to achieve better homogenization (melting) of the welding material towards the periphery.

\section{CONCLUSIONS}

The following conclusions emerged from this research study:

1) The parameters of the laser welding device used in this study led to satisfactory tensile strength of the laser welded specimens, as although having lower tensile strength than the non-welded specimens, they did not show a statistically significant difference.

2) The presence or absence of argon inert gas during laser welding did not show a statistically significant difference. Thus, the presence of argon inert gas does not affect the quality of the laser weld.

3) The material utilised to manufacture the specimens had a statistically significant effect on the tensile strength, as the $\mathrm{Cr}$-Co alloy specimens had higher tensile strength than the Cr-Ni welded specimens.

4) The morphology of the circular stratification of the laser welding material generated voids in the welded area, but both their arrangement and the intermediate stratified bridges of welded material observed did not significantly affect the tensile strength of the specimens.

5) The process of laser welding applied in daily practice (separation of specimen, formation of two cones in contact, laser welding of the two cones, filling the gap via laser welding), is considered to be satisfactory.

\section{CONFLICTS OF INTEREST}

The authors declare no conflicts of interest regarding the publication of this paper.

\section{REFERENCES}

1. Hero, H., Syverud, M., Gjonnes, J. and Horst, J.A. (1984) Ductility and Structure of Some Cobalt-Base Dental Casting Alloys. Biomat, 5, 201-208. https://doi.org/10.1016/0142-9612(84)90016-4

2. Asgar, K. and Peyton, F.A. (1961) Effect of Microstructure on the Physical Properties of Cobalt-Base Alloys. Journal of Dental Research, 40, 63-72. https://doi.org/10.1177/00220345610400012501

3. Asgar, K. and Peyton, F.A. (1961) Effect of Casting Conditions on Some Mechanical Properties of Cobalt-Base Alloys. Journal of Dental Research, 40, 73-86. https://doi.org/10.1177/00220345610400012601

4. McCabe, J.F. and Walls, A.W.G. (2008) Applied Dental Materials. 9th Edition, Blackwell Publishing Ltd., Oxford.

5. Brown, D., Braden, M., Miller, M., Causton, B.E., Prosser, H.J., Combe, E.C., et al. (1981) Dental Materials, 1979 Literature Review Part I. Journal of Dentistry, 9, 177-209. https://doi.org/10.1016/0300-5712(81)90056-7

6. Nikellis, I., Levi, A. and Zinelis, S. (2005) Effect of Soldering on the Metal-Ceramic Bond Strength of an Ni-Cr Base Alloy. Journal of Prosthetic Dentistry, 94, 435-439. https://doi.org/10.1016/j.prosdent.2005.09.012

7. Angelini, E., Bonino, P. and Pezzoli, M. (1988) Corrosion Resistance of Solder Joints for Removable Partial Dentures. Dental Materials, 4, 255-260. https://doi.org/10.1016/S0109-5641(88)80019-8

8. Gordon, T.E. and Smith, D.L. (1970) Laser Welding of Prostheses-An Initial Report. Journal of Prosthetic Dentistry, 24, 472-476. https://doi.org/10.1016/0022-3913(70)90087-9

9. da Silva Barbosa, J., de Lima, E.D., de Melo, J.B.C.A., Batista, A.U.D., Neto, J.P.S. and da Silva, H.F.V. (2021) Fractographic Analysis of Two Fractured Removable Partial Denture Metal Frameworks. Research, Society and Development, 10, 1-9. https://doi.org/10.33448/rsd-v10i10.18370

10. Kelly, J.R. and Rose, T.C. (1983) Nonprecious Alloys for Use in Fixed Prosthodontics, a Literature Review. Journal of Prosthetic Dentistry, 49, 363-370. https://doi.org/10.1016/0022-3913(83)90279-2 
11. Wataha, J.C. (2002) Alloys for Prosthodontic Restorations. Journal of Prosthetic Dentistry, 87, 351-363. https://doi.org/10.1067/mpr.2002.123817

12. Tartari, A., Clark, R.K.F., Juszczyk, A.S. and Radford, D.R. (2010) Tensile Strength of Laser Welded Cobalt-Chromium Alloy with and without an Argon Atmosphere. European Journal of Prosthodontics and Restorative Dentistry, 18, 60-65.

13. Bertrard, C., Le Petitcorps, Y., Albingre, L. and Dupuis, V. (2001) The Laser Welding Technique Applied to the Non Precious Dental Alloys Procedure and Results. British Dental Journal, 190, 255-257. https://doi.org/10.1038/sj.bdj.4800942a

14. Pop, D., Negrutiu, M., Sinescu, C., Demian, C., Todea, C., Rominu, M. and Balabuc, C. (2007) Different Types of Laser Welding in Dental Technology. TMJ, 57, 184-186.

15. NaBadalung, D.P. and Nicholls, J.I. (1998) Laser Welding of a Cobalt-Chromium Removable Partial Denture Alloy. Journal of Prosthetic Dentistry, 79, 285-290. https://doi.org/10.1016/S0022-3913(98)70239-2

16. Lee, J.H., Choi, S.K. and Hong, M.H. (2015) The Metallurgical Characteristics of Non-Precious Alloys Using Nd, YAG Laser Welding. BioMed Research, 19, 1-10. https://doi.org/10.1186/s40824-015-0047-x

17. Watanabe, I. and Topham, D.S. (2006) Laser Welding of Cast Titanium and Dental Alloys Using Argon Shielding. Journal of Prosthodontics, 15, 102-107. https://doi.org/10.1111/j.1532-849X.2006.00082.x

18. Rezaei, S.M., Heidarifar, H., Arezodar, F., Azary, A. and Mokhtaryhoee, S. (2011) Influence of Connector Width on the Stress Distribution of Posterior Bridges Under Loading. Journal of Dentistry, 8, 67-74.

19. Reimann, L., Zmudzski, J. and Dobranski, L.A. (2015) Strength Analysis of a Three-Unit Dental Bridge Framework with the Finite Element Method. Acta of Bioengineering and Biomechanics, 17, 51-59.

20. Morris, H.F., Asgar, K., Rowe, A.P. and Nasjleti, C.E. (1979) The Influence of Heat Treatments on Several Types of Base-Metal Removable Partial Denture Alloys. Journal of Prosthetic Dentistry, 41, 388-395. https://doi.org/10.1016/0022-3913(79)90034-9

21. Dharmar, S., Rathnasamy, R.J. and Swaminathan, T.N. (1993) Radiographic and Metallographic Evaluation of Porosity Defects and Grain Structure of Cast Chromium Cobalt Removable Partial Dentures. Journal of Prosthetic Dentistry, 69, 369-373. https://doi.org/10.1016/0022-3913(93)90182-N

22. Lewis, A.J. (1978) Radiographic Evaluation of Porosities in Removable Partial Denture Castings. Journal of Prosthetic Dentistry, 39, 278-281. https://doi.org/10.1016/S0022-3913(78)80095-X

23. Lewis, A.J. (1978) Failure of Removable Partial Denture Castings during Service. Journal of Prosthetic Dentistry, 39, 147-149. https://doi.org/10.1016/S0022-3913(78)80011-0

24. Van Noort, R. and Lamb, D.J. (1984) A Scanning Electron Microscope Study of Co-Cr Partial Dentures Fractured in Service. Journal of Dentistry, 12, 122-126. https://doi.org/10.1016/0300-5712(84)90045-9

25. Elarbi, E.A., Ismail, Y.H., Azarbal, M. and Saini, T.S. (1985) Radiographic Detection of Porosities in Removable Partial Denture Castings. Journal of Prosthetic Dentistry, 54, 674-677. https://doi.org/10.1016/0022-3913(85)90248-3

26. Lewis, A.J. (1975) Microporosity in Casting Alloys. Australian Dental Journal, 20, 161-166. https://doi.org/10.1111/j.1834-7819.1975.tb04361.x

27. Eisenburger, M. and Addy, M. (2002) Radiological Examination of Dental Castings-A Review of the Method and Comparisons of the Equipment. Journal of Oral Rehabilitation, 29, 609-614. https://doi.org/10.1046/j.1365-2842.2002.00938.x

28. Wictorin, L., Julin, P. and Mollersten, L. (1979) Roentgenological Detection of Casting Defects in Cobalt-Chromium Alloy Frameworks. Journal of Oral Rehabilitation, 6, 137-146. 
https://doi.org/10.1111/j.1365-2842.1979.tb01273.x

29. Morris, H., Farah, J.W., Craig, R.G. and Hood, J.A. (1976) Stress Distribution within Circumferential Clasp Arms. Journal of Oral Rehabilitation, 3, 387-394. https://doi.org/10.1111/j.1365-2842.1976.tb01453.x

30. Srimaneepong, V., Yoneyama, T., Kobayashi, E., Doi, H. and Hanawa, T. (2008) Comparative Study on Torsional Strength, Ductility and Fracture Characteristics of Laser-Welded $\alpha+\beta$ Ti-6Al-7Nb Alloy, CP Titanium and Co-Cr Alloy Dental Castings. Dental Materials, 24, 839-845. https://doi.org/10.1016/j.dental.2007.10.002

31. Zupancic, R., Legat, A. and Funduk, N. (2006) Tensile Strength and Corrosion Resistance of Brazed and Laser-Welded Cobalt-Chromium Alloy Joints. Journal of Prosthetic Dentistry, 96, 273-282. https://doi.org/10.1016/j.prosdent.2006.08.006

32. Bertrand, C., Le Petitcorps, Y., Albingre, L. and Dupuis, V. (2001) The Laser Welding Technique Applied to the Non Precious Dental Alloys Procedure and Results. British Dental Journal, 190, 255-257. https://doi.org/10.1038/sj.bdj.4800942

33. Asgar, K. and Allan, F.C. (1968) Microstructure and Physical Properties of Alloys for Partial Denture Castings. Journal of Dental Research, 47, 189-197. https://doi.org/10.1177/00220345680470020201

34. Baba, N., Watanabe, I., Liu, J. and Atsuta, M. (2004) Mechanical Strength of Laser-Welded Cobalt-Chromium Alloy. Journal of Biomedical Materials Research, 69, 121-124. https://doi.org/10.1002/jbm.b.10082

35. Han, S.K. and Margolin, H. (1989) Void Formation, Void Growth and Tensile Fracture of Plain Carbon Steel and a Dual-Phase Steel. Materials Science and Engineering A, 112, 133-141. https://doi.org/10.1016/0921-5093(89)90352-3

36. Bertrand, C., Le Petitcorps, Y., Albingre, L. and Dupuis, V. (2004) Optimization of Operator and Physical Parameters for Laser Welding of Dental Materials. British Dental Journal, 196, 413-418. https://doi.org/10.1038/sj.bdj.4811138

37. Luthy, H., Marinello, C.P., Reclaru, L. and Scharer, P. (1996) Corrosion Considerations in the Brazing Repair of Cobalt-Based Partial Dentures. Journal of Prosthetic Dentistry, 75, 515-524. https://doi.org/10.1016/S0022-3913(96)90456-4

38. Kokolis, J., Chakmakchi, M., Theocharopoulos, A., Prombonas, A. and Zinelis, S. (2015) Mechanical and Interfacial Characterization of Laser Welded Co-Cr Alloy with Different Joint Configurations. The Journal of Advanced Prosthodontics, 7, 39-46. https://doi.org/10.4047/jap.2015.7.1.39

39. Al Jabbari, Y.S., Koutsoukis, T., Barmpagadaki, X., El-Danaf Ehab, A., Fournelle, R.A. and Zinelis, S. (2015) Effect of Nd, YAG Laser Parameters on the Netration Depth of a Representative Ni-Cr Dental Casting Alloy. Journal of Lasers in Medical Sciences, 30, 909-914. https://doi.org/10.1007/s10103-013-1502-3 